\title{
Urgent bedside echocardiography in diagnosis of acute massive pulmonary embolism presenting with cardiogenic shock - case report
}

\author{
Irena Peovska*, Elizabeta Srbinovska-Kostovska, Marijan Bosevski \\ State Hospital - University Clinical Center, Skopje, Republic of Macedonia
}

We are presenting the case of a 51-year-old man who has been admitted at our clinic with dyspnea, cardiogenic shock and severe pain and swelling of the left leg. At the admission he was cyanotic, severely hypotensive, with tachypnea, an oxygen saturation of $70 \%$. An acute massive pulmonary embolism was suspected, and an emergency bedside transthoracic echocardiogram was performed. Bedside echocardiography showed significantly enlarged right ventricle (46 $\mathrm{mm}$ tricuspid annular size), hypokinesia of the free right ventricular wall and increased pulmonary artery size (34 mm), with signs of RV overload. There was large mobile thrombus with dimensions $(34 \times 37 \mathrm{~mm})$ prolabing from right ventricle to the right atrium. Severe tricuspid regurgitation, with dilated right atrium and dilated vena cava inferior $-24 \mathrm{~mm}$ were found. Indirect estimation of the pulmonary hypertension with the value of the maximal velocity of the tricuspid regurgitation showed increased pulmonary pressure (estimated systolic pulmonary atrial pressure - SPAP was $59 \mathrm{mmHg}$ ). Color Duplex sonography of lower extremities was also performed at the bed site with the finding of non compressible left common femoral vein, which was consistent with the deep vein thrombosis. D-dimmers were significantly increased (>4.500 nq/l). Multislice computed tomography performed next day confirmed central filling defect of the left pulmonary artery consistent with acute thrombus. Based on the patient's clinical condition and the echocardiographic fin- dings, he has been treated with fibrinolysis therapy with alteplase. Control echocardiography performed three days after fibrinolytic therapy showed decrease in SPAP pressure from $59 \mathrm{mmHg}$ to $40 \mathrm{mmHg}$, moderate tricuspid regurgitation, normal right ventricular size and function. The patient had excellent clinical recovery and was discharged from the hospital after 20 days. This case confirms the role of urgent bedside echocardiography in fast diagnosis of acute pulmonary embolism, which leads to proper management and favorable patient outcome.

KEYWORDS: urgent echocardiography, pulmonary embolism, cardiogenic shock.

\section{Received: $20^{\text {th }}$ Mar 2013}

*Address for correspondence: State Hospital - University Clinical Center, Vodnjanska 17, 1000 Skopje, Republic of Macedonia.

Phone: +389-2-314-71-47

E-mail: ipeovska@yahoo.com

\section{Literature}

1. Guidelines on the diagnosis and management of acute pulmonary embolism. The Task Force for the Diagnosis and Management of Acute Pulmonary Embolism of the European Society of Cardiology (ESC). Eur Heart J. 2008;29(18):2276-315.

2. Matthews JC, McLaughlin V. Acute right ventricular failure in the setting of acute pulmonary embolism or chronic pulmonary hypertension: a detailed review of the pathophysiology, diagnosis, and management. Curr Cardiol Rev. 2008;4(1):49-59.

3. Mookadam F, Jiamsripong P, Goel R, Warsame TA, Emani UR, Khandheria BK. Critical appraisal on the utility of echocardiography in the management of acute pulmonary embolism. Cardiol Rev. 2010;18(1):29-37.

4. Cohen R, Loarte P, Navarro V, Mirrer B. Echocardiographic findings in pulmonary embolism: an important guide for the management of the patient. World Journal of Cardiolovascular Diseases 2012;2;161-4- 